\title{
Strategi Pemasaran Jasa Pendidikan dalam Meningkatkan Animo Masyarakat pada Masa Pandemi Covid-19
}

\author{
Mahmud MY', Riftiyanti Savitri ${ }^{2}$, \& Lesiana Oktorita ${ }^{3}$ \\ Universitas Islam Negeri Sulthan Thaha Saifuddin, Jambi \\ *corresponding author: mahmudyasin95@yahoo.com
}

\begin{abstract}
:
This research aims to find out the management of marketing of educational services in increasing public interest during the Covid-19 pandemic. This research uses descriptive qualitative research methods. Data is collected through observations, interviews, and documentation. The results of the study showed that the marketing of ma Al-Azhar Muaro Bungo education services during the Covid-19 pandemic was carried out by applying the concept of educational services marketing mix including marketing quality graduate products and karimah; price (tuition fee) is determined by the adjustment of the average economy of the student's parents; the place or location of the madrassa is in a strategic location; madrassa promotion is carried out directly and indirectly; Professional human resources and adequate facilities and infrastructure; The process of delivering educational services includes the delivery of facilities and facilities, learning activities, and extracurricular activities.
\end{abstract}

KEYWORDS: Management; educational marketing; community interest.

\begin{abstract}
ABSTRAK:
Penelitian ini bertujuan untuk mengetahui pengelolaan pemasaran jasa pendidikan dalam meningkatkan animo masyarakat selama masa pandemic Covid-19. Penelitian ini menggunakan metode penelitian kualitatif deskriptif. Data dikumpulkan melalui observasi, wawancara, dan dokumentasi. Hasil penelitian menunjukkan pemasaran jasa pendidikan MA Al-Azhar Muaro Bungo pada masa pandemi Covid-19 dilaksanakan dengan menerapkan konsep bauran pemasaran jasa pendidikan meliputi pemasaran produk lulusan yang bermutu dan berakhlak karimah; price (biaya sekolah) ditentukan dengan penyesuaian rata-rata ekonomi orang tua siswa; tempat atau lokasi madrasah berada di lokasi strategis; promosi madrasah dilakukan secara langsung langsung dan tidak langsung; SDM yang professional serta sarana dan prasarana yang memadai; proses penyampaian jasa pendidikan meliputi penyampaian fasilitas sarana dan prasaran, kegiatan pembelajaran, dan kegiatan ekstrakulikuler.
\end{abstract}

KATA KUNCI: Manajemen; pemasaran pendidikan; animo masyarakat.

Copyright (c) Published by Program Studi Manajemen Pendidikan Islam Fakultas Tarbiyah dan Keguruan

Universitas Islam Negeri Sulthan Thaha Saifuddin jambi Mendalo Darat, Muaro Jambi, 36361, Indonesia 


\section{PENDAHULUAN}

Persaingan antar lembaga pendidikan semakin tinggi. Hal ini disebabkan masuknya era globalisasi yang menjadi pemicu kekuatan (driver forces), sehingga menimbulkan paradigma baru, yaitu dunia tidak mengenal batas-batas teritorial kedaulatan sebuah negara/bangsa. Borderless world tersebut memberi dampak pada semua aspek kehidupan masyarakat termasuk pada dunia pendidikan, yaitu terciptanya persaingan yang semakin tinggi antar lembaga pendidikan, terutama di masa pandemic Covid-19 (Atika \& Imam Machali, 2016).

Pandemic Covid-19 yang mulai muncul pada tahun 2019 masih menjadi ancaman dan berpotensi besar membuat hasil pendidikan menjadi lebih buruk. Pandemi telah memberi dampak besar pada pendidikan dengan menutup sekolah hampir di setiap wilayah di Indonesia (Ali Murfi, et.all., 2020). Lembaga pendidikan dituntut untuk mengatasi guncangan ini, dan mengubah krisis menjadi peluang. Sekolah/madrasah harus mampu berkembang dan mengubah diri dengan cepat agar dapat terus eksis dan bersaing dengan lembaga pendidikan formal lainnya. Peningkatan mutu lembaga dan pelayanan prima harus digalakkan demi memenuhi tuntutan stakeholder. Madrasah perlu menerapkan strategi pemasaran yang tepat melalui segmentasi dan positioning agar dapat sukses memenangkan persaingan di dunia pendidikan (Atika \& Imam Machali, 2016).

Pada pertengahan tahun 2021, pemerintah Indonesia mulai kembali memberlakukan kebijakan pembelajaran tatap muka bagi siswa di sekolah/madrasah. Pengelola sekolah/madrasah perlu merencanakan pembukaan sekolah untuk mencegah putus sekolah, memastikan kondisi sekolah yang sehat, dan menggunakan teknik baru untuk mempromosikan pemulihan belajar cepat di bidang-bidang utama begitu siswa kembali ke sekolah, terutama dalam meningkatkan animo masyarakat. Pengelola sekolah/madrasah juga dapat mengembangkan strategi pemasarannya agar mutu lembaga pendidikannya semakin meningkat dan dapat menarik banyak siswa. Manajemen pemasaran pendidikan sebaiknya diatur secara optimal agar mampu bersaing dengan lembaga pendidikan lainnya. 
Pemasaran jasa pendidikan merupakan suatu kegiatan atau proses sosial yang dilakukan secara manajerial, baik dilakukan oleh individu atau secara kelompok, untuk mendapatkan hasil sesuai yang dibutuhkan dan diinginkan oleh lembaga pendidikan melalui bentuk penawaran dengan pihak lain yang berkepentingan (Kotler, 2004). Dalam manajemen pemasaran pendidikan terdapat bauran (alat) pemasaran jasa pendidikan yaitu produk, harga, lokasi, promosi, sumber daya manusia, bukti fisik, dan proses jasa pendidikan (Wahyudi, 2017).

Manajemen pemasaran pendidikan memiliki peran penting dan strategis bagi kelangsungan sebuah lembaga pendidikan, terutama lembaga pendidikan Islam, manajemen pemasaran pendidikan harus bertitik tolak dari kebutuhan dan keinginan konsumen (masyarakat) dengan memperkirakan sekaligus menentukan kebutuhan dan keinginan masyarakat serta penyerahan jasa yang memuaskan secara efektif dan efesien. Hal ini tentu menuntut lembaga pendidikan agar mampu bersaing dalam proses pemasaran pendidikan. Apabila lembaga pendidikan memiliki pemasaran pendidikan yang baik dengan didukung oleh fasilitas yang memadai, maka kualitas lembaga pendidikan akan semakin meningkat. Akan tetapi, bila lembaga pendidikan lemah dalam pemasaran pendidikan, maka dapat dipastikan akan berkurang peminatnya, apalagi dari segi kualitas dan prestasinya.

Pelaksanaan strategi pemasaran jasa pendidikan sekolah yang tepat akan memicu tumbuh kembangnya pendidikan bagi lembaga pendidikan. Pada akhirnya hasil pendidikan yang berupa sumber daya manusia dapat digunakan untuk memenuhi kebutuhan masyarakat di luar maupun di dalam bidang pendidikan itu sendiri. Apabila produsen tidak mampu memasarkan hasil produksinya, dalam hal ini jasa pendidikan disebabkan mutunya tidak dapat memuaskan konsumen, maka produksi jasa yang ditawarkan tidak akan diminati para konsumen.

Strategi pemasaran pendidikan diadopsi dari dunia bisnis. Istilah marketing terfokus pada sisi kepuasan konsumen dengan memakai dasar pemikiran yang logis, jika konsumennya tidak puas, berarti marketingnya gagal. Dengan kata lain, jika lembaga pendidikan yang memproses jasa pendidikan tidak mampu memuaskan users educations sesuai dengan need pasar, maka lembaga pendidikan tersebut tidak dapat mempertahankan keeksisannya (Minarti, 2011). Jika logika corporate ini dipakai dalam dunia 
pendidikan, maka lembaga pendidikan dapat dimaknai sebagai sebuah lembaga yang bergerak di bidang layanan jasa pendidikan yang kegiatannya melayani konsumen berupa siswa, mahasiswa, maupun masyarakat umum yang dikenal sebagai stakeholder. Sebab, etika pemasaran dalam dunia pendidikan adalah menawarkan mutu layanan intelektual dan pembentukan watak secara menyeluruh (Hidayat dan Machali, 2012).

Madrasah Aliyah (MA) Al-Azhar Muaro Bungo adalah bagian dari mitra pemerintah untuk memajukan pendidikan di Indonesia. Secara ringkas MA AlAzhar Muaro Bungo adalah struktur organisasi atau lembaga yang berada dalam naungan kementrian Agama dan Dinas Pendidikan. Berdasarkan hasil survei awal, ditemukan bahwa jumlah pendaftar dan jumlah siswa yang diterima di MA Al-Azhar Muaro Bungo meningkat di setiap tahunnya mulai dari tahun 2018-2020, namun terjadi penurunan di tahun 2021. Pada tahun 2018 jumlah siswa yang diterima adalah 95 siswa, tahun 2019 terdapat 110 siswa yang diterima, tahun 2020 terdapat 150 siswa yang diterima, pada tahun 2021 MA AlAzhar Muaro Bungo menerima 89 siswa baru. Penurunan jumlah siswa yang diterima pada tahun 2021 di MA Al-Azhar Muaro Bungo disebabkan adanya persaingan antar lembaga pendidikan dan semakin banyaknya sekolah-sekolah berbasis Islam di Muaro Bungo. Selain itu, angka jumlah pendaftar dan jumlah siswa yang diterima memiliki kesamaan nilai, dikarenakan pendaftaran akan ditutup ketika kuota siswa yang diterima telah terpenuhi, sehingga nilai angka jumlah pendaftar dan jumlah siswa yang diterima sama.

Dalam hal ini MA Al-Azhar Muaro Bungo harus mempunyai strategi atau upaya-upaya yang digunakan dalam pemasaran pendidikan, melalui bauran pemasaran seperti produk, tempat, harga, dan lain sebagainya. MA AlAzhar Muaro Bungo dapat menerapkan strategi pemasaran untuk meningkatkan animo pendaftar dan membuat inovasi-inovasi baru agar pelayanan di madrasah dapat memuaskan pelanggan atau siswa. Penelitian ini diharapkan dapat memberikan informasi secara objektif terkait proses manajemen yang dilakukan mulai dari tahapan perencanaan, pengorganisasian, pelaksanaan dan evaluasi yang diterapkan, sehingga dapat dipergunakan sebagai upaya meningkatkan mutu sekolah terutama berkaitan dengan penerimaan peserta didik baru di MA Al-Azhar Muaro Bungo. 


\section{METODE}

Penelitian ini menggunakan metode deskriptif kualitatif. Data dikumpulkan melalui observasi, wawancara, dan dokumentasi. Teknik analisis menggunakan teknik analisis yang dikemukakan oleh Miles dan Huberman yakni reduksi data, penyajian data, dan penarik kesimpulan (Sugiyono, 2014). Teknik keabsahan data menggunakan teknik triangulasi yang bertujuan untuk mengecek kebenaran dan keabsahan data-data yang diperoleh di lapangan dalam meningkatkan animo masyarakat di MA Al-Azhar Muaro Bungo.

\section{HASIL PENELITIAN DAN PEMBAHASAN}

Upaya sekolah dalam meningkatkan animo masyarakat di MA Al-Azhar Muaro Bungo pada masa pandemic Covid-19 menggunakan konsep 7 (tujuh) bauran pemasaran jasa pendidikan. Konsep 7 (tujuh) bauran pemasaran tersebut meliputi 4 (empat) "P" yaitu produk (product), harga (price), tempat (place), dan promosi (promotion) dan ditambahkan dengan 3 (tiga) "P" lainnya yaitu sumber daya manusia (people), bukti fisik (physical evidence), dan proses (process) (Kotler dan Amstrong, 2008).

a. Produk (Product)

Menurut Kotler, produk adalah segala sesuatu yang dapat ditawarkan produsen untuk diperhatikan, diminta, dicari, dibeli, digunakan atau dikonsumsi pasar sebagai pemenuhan kebutuhan atau keinginan pasar yang bersangkutan. Produk dalam kontek jasa pendidikan madrasah adalah jasa yang ditawarkan kepada pelanggan berupa reputasi, prospek, dan variasi pilihan. Lembaga pendidikan yang mampu bertahan dan mampu memenangkan persaingan jasa pendidikan adalah lembaga yang dapat menawarkan reputasi, prospek, mutu pendidikan yang baik, dan peluang yang cerah bagi para siswa untuk menentukan pilihan-pilihan yang diinginkannya atau dengan kata lain produk pendidikan merupakan segala sesuatu yang dapat ditawarkan kepada masyarakat yang bertujuan untuk memenuhi kebutuhan dan keinginannya.

MA Al-Azhar Muaro Bungo berusaha mengelola proses sebaik mungkin dengan menghasilkan produk lulusan yang bermutu. Mutu ditunjukkan dengan kemampuan rata-rata siswa dalam berprestasi baik prestasi akademik maupun non akademik serta memiliki karakter yang 
baik. Dalam pelaksanaannya kualitas input produk sangat mempengaruhi kualitas produk yang dihasilkan. Rata-rata prestasi awal, jumlah siswa, dukungan SDM dan sarana prasarana yang memadai MA Al-Azhar Muaro Bungo memiliki potensi yang besar untuk menghasilkan produk yang bermutu. Dalam bidang non akademik MA Al-Azhar Muaro Bungo telah menunjukkan prestasinya dengan menjuarai beberapa bidang perlombaan. Pengembangan prestasi bidang non akademik menjadi salah satu kebijakan stategis dalam pemenuhan minat dan bakat siswa. Mutu produk juga dapat ditunjukkan melalui pemasaran tamatan.

b. Harga (Price)

Price merupakan elemen yang berjalan sejajar dengan mutu produk, dimana apabila mutu produk baik, maka calon siswa/mahasiswa berani membayar lebih tinggi sepanjang dirasa dalam batas kejangkauan pelanggan pendidikan. Prinsip utama dalam dalam menentukan harga adalah menghitung keseluruhan biaya yang diperlukan ditambahkan benefit yang dbutuhkan untuk kepentingan pengembangan dalam beberapa tahun.

Dalam menentukan anggaran SPP, MA Al-Azhar Muaro Bungo selalu menyesuaikan dengan rata-rata ekonomi orang tua siswa. Hal ini dilakukan pada saat rapat pembahasan program kerja dan menentukan kebijakan di dalam madrasah. Strategi penentuan harga jasa pendidikan sering kali tidak berhasil karena ada keterkaitan yang jelas antara harga jasa dan nilai jasa. Tiga strategi untuk menangkap dan mengomunikasikan nilai jasa yaitu pengurangan ketidakpastian, peningkatan hubungan, dan kepemimpinan biaya. Lebih lanjut untuk menentukan harga jasa pendidikan pada pelanggan jasa pendidikan, beberapa di antaranya adalah penentuan harga dalam dua bagian yaitu kebijakan pembayaran secara bertahap dalam dua waktu dan diskon kuantitas yaitu potongan harga bagi siswa dengan karakteristik khusus, misalnya kurang mampu.

c. Tempat (Place)

Place adalah letak lokasi sekolah mempunyai peranan yang sangat penting, karena lingkungan dimana jasa disampaikan merupakan bagian dari nilai dan manfaat jasa yang dipersepsikan cukup berperan sebagai 
bahan pertimbangan dalam menentukan pilihan. Dalam hal ini penyedia jasa perlu mempertimbangkan faktor-faktor diantaranya akses yaitu kemudahan mencapai lokasi, vasibilitas yaitu lembaga tersebut dapat terlihat dengan jelas keberadaan fisiknya, lalu lintas dalam arti tingginya tingkat kemacetan akan mempengaruhi minat kustomer terhadap jasa tersebut, tempat parkir yang luas, ketersediaan lahan untuk kemungkinan perluasan usaha, persaingan yaitu dengan memperhitungkan lokasi pesaing, dan ketentuan pemerintah tentang peruntukan lahan sesuai dengan standar pelayanan minimum yang harus di anut oleh setiap lembaga pendidikan.

MA Al-Azhar Muaro Bungo berada di lokasi yang strategis karena dekat dengan pusat kota namun dengan suasana yang nyaman dan menyejukkan karena dikelilingi oleh persawahan milik warga. Penting bagi lembaga pendidikan untuk mempublikasikan lokasi strategis yang dimilikinya. Tanpa informasi yang jelas masyarakat calon pengguna pendidikan utamanya luar daerah kurang mengetahui bahwa lokasi yang dimiliki sekolah tertentu sangat mendukung bagi kemudahan dan kenyaman siswa dalam belajar mengajar.

d. Promosi (Promotion)

Promotion merupakan suatu bentuk komunikasi pemasaran yaitu aktifitas pemasaran yang berusaha menyebarkan informasi, mempengaruhi/membujuk, dan/atau mengingatkan pasar sasaran atas lembaga dan produknya agar bersedia menerima, membeli dan loyal pada produk yang ditawarkan oleh lembaga tersebut. aktivitas tentang bagaimana memberitahu pelanggan tentang keberadaan produk/jasa. Aspek yang harus dipertimbangkan adalah bentuk komunikasi, khususnya iklan (advertising), penjualan personal (personal selling), promosi penjualan (sales promotion) dan publisitas penyedia jasa tersebut, membujuk customer untuk membeli dan menggunakan jasa tersebut.

Promosi ini lebih diarahkan pada penyedia jasa pendidikan sehingga pengaruh image tersebut berperan penting terhadap penjatuhan pilihan customer. Promosi yang berlebihan mempunyai hubungan korelatif yang negatif terhadap daya tarik peminat. Promosi yang dilakukan oleh MA Al-Azhar Muaro Bungo meliputi promosi langsung 
maupun promosi tidak langsung. Kegiatan promosi langsung yaitu dengan cara presentasi ke sekolah SMP/MTs yang menjadi target untuk mensosialisasikan program-program unggulan sekolah atau menjalin sinergi kegiatan lainnya seperti sumbangan pengalihan hewan kurban, baksos dan lain-lain. Promosi tidak langsung dilakukan dengan memanfaatkan IT, dan memasang spanduk, maupun menyebar brosur. Selain itu, dalam kerangka promosi sekolah, MA Al-Azhar Muaro Bungo juga menerapkan strategi kemitraan dengan sekolah-sekolah SMP/MTs yang berpotensi memfasilitasi anak didiknya melanjutkan ke MA Al-Azhar Muaro Bungo. Strategi kemitraan antar lembaga berfungsi untuk memudahkan komunikasi dan birokrasi dalam kegiatan pemasaran jasa pendidikan.

e. Sumber Daya Manusia (People)

People adalah semua pelaku yang memainkan peranan dalam penyajian jasa sehingga dapat mempengaruhi persepsi pembeli. Elemenelemen dari people adalah pegawai perusahaan, konsumen, dan konsumen lain dalam lingkungan jasa. Semua sikap dan tindakan karyawan, bahkan cara pakaian karyawan dan penampilan karyawan mempunyai pengaruh terhadap persepsi konsumen atau keberhasilan penyampaian.

Adapun sumber daya manusia adalah semua orang atau pelaku yang terlibat dalam proses penyampaian jasa konsumen serta mempengaruhi persepsi konsumen, seperti para personal penyedia jasa, pelanggan, dan para pelanggan lain yang terkait dengan jasa tersebut. Sumber daya manusia dalam sebuah lembaga sekolah dikelompokkan menjadi tiga, yaitu administrator, guru, dan pegawai, yang perlu memiliki kompetensi yang tinggi, karena pada pelaksanaannya tiga sumber daya tersebut yang secara langsung menyampaikan jasa kepada para siswa, sehingga puas tidaknya siswa tergantung bagaimana jasa tersebut tersampaikan.

MA Al-Azhar Muaro Bungo memiliki tenaga pengajar yang professional. Keunggulan sumber daya manusia dengan ragam kompetensi yang dimiliki adalah salah satu modal utama bagi pengembangan kelembagaan. Dalam pengelolaan sumber daya MA Al- 
Azhar Muaro Bungo mengacu kepada Standar Nasional Pendidikan yang memuat kriteria minimal tentang komponen pendidikan yang memungkinkan setiap jenjang dan jalur pendidikan untuk mengembangkan pendidikan secara optimal sesuai dengan karakteristik dan kekhasan programnya.

f. Bukti fisik (Physical Evidence)

Physical evidence merupakan sarana dan prasarana yang mendukung proses penyampaian jasa pendidikan sehingga akan membantu tercapainya janji lembaga kepada pelanggannya. Sarana fisik ini merupakan suatu hal yang secara nyata turut mempengaruhi keputusan konsumen untuk membeli dan menggunakan prosuk jasa yang ditawarkan. Unsur-unsur yang termasuk di dalam sara fisik antara lain lingkungan fisik, dalam hal ini bangunan fisik, peralatan, perlengkapan, logo, warna, dan barang-barang lainnya yang disatukan dengan service yang diberikan seperti tiket,sampul, label, dan lain sebagainya. MA AlAzhar Muaro Bungo dilengkapi dengan sarana dan prasarana yang baik untuk menunjang kegiatan pembelajaran siswa.

g. Proses (Process)

Proses penyampaian jasa pendidikan merupakan inti dari seluruh pendidikan, kualitas dalam seluruh elemen yang menunjang proses pendidikan menjadi hal yang sangat penting untuk menentukan keberhasilan proses pembelajaran sekaligus sebagai bahan evaluasi terhadap pengelolaan lembaga pendidikan dan citra yang terbantuk akan membentuk sirkulasi dalam merekrut pelanggan pendidikan.

Kesadaran guru akan tugas dan tanggungjawabnya, menuntut kemauan untuk terus belajar dan berkembang. Oleh karena itu, kesanggupan berusaha dan belajar sendiri merupakan kecakapan modal dasar yang perlu dikembangkan karena selain memperbaiki pengetahuan dan kecakapan sekaligus memperkuat jabatan guru sebagai pendidik yang profesional. Proses ini selalu menjadi fokus kebijakan MA Al-Azhar Muaro Bungo dengan membiasakan budaya disiplin, budaya berkarya dan kerjasama. 
Proses pendidikan yang baik juga mempertimbangkan kepuasan siswa dalam pelayanan aktualisasi melalui kegiatan intrakurikuler melalui Organisasi Siswa Intra Sekolah (OSIS) maupun kegiatan ekstrakurikuler. Kegiatan ekstrakurikuler membutuhkan pola penanganan tepat dan kompetensi pembina yang kompeten. MA Al-Azhar Muaro Bungo telah memfasilitasi ragam jenis kegiatan ekstrakurikuler sesuai dengan aspirasi siswa. Proses pendampingan dan pembinaan yang baik perlu ditingkatkan dengan cara menyediakan pendamping yang memiliki kompetensi relevan baik dari dalam maupun luar sekolah. Proses penyampaian jasa pendidikan MA Al-Azhar Muaro Bungo meliputi penyampaian fasilitas sarana dan prasaran penunjang KBM, kegiatan pembelajaran, kegiatan ekstrakulikuler, dan kegiatan di bidang keagamaan maupun pendidikan umum lainnya.

\section{SIMPULAN}

Upaya lembaga pendidikan dalam meningkatkan animo masyarakat di MA Al-Azhar Muaro Bungo pada masa pandemi Covid-19 dilaksanakan dengan menerapkan konsep bauran pemasaran jasa pendidikan. Produk yang dihasilkan dari MA Al-Azhar Muaro Bungo adalah lulusan yang bermutu dan berakhlak karimah. Price (biaya sekolah) ditentukan dengan penyesuaian ratarata ekonomi orangtua siswa. Tempat atau lokasi madrasah berada di lokasi strategis, dekat dengan pusat kota masih dengan suasana yang nyaman dan menyejukkan karena dikelilingi oleh persawahan milik warga. Promosi madrasah dilakukan secara langsung langsung dan tidak langsung. Madrasah memiliki SDM yang professional dan dilengkapi dengan sarana dan prasarana yang memadai untuk menunjang kegiatan pembelajaran siswa. Proses penyampaian jasa pendidikan meliputi penyampaian fasilitas sarana dan prasaran penunjang KBM, kegiatan pembelajaran, kegiatan ekstrakulikuler, dan kegiatan di bidang keagamaan maupun pendidikan umum lainnya.

\section{REFERENSI}

Atika dan Imam Machali. 2016. "Segmentasi dan PositioningJasa Pendidikandi MAN Yogyakarta III." Manageria: Jurnal Manajemen Pendidikan Islam, 1(2); 153-168. 
Hidayat, Ara dan Imam Machali. 2012. Pengelolaan Pendidikan (Konsep, Prinsip, dan Aplikasi dalam Mengelola Sekolah dan Madrasah). Yogyakarta: Kaukaba.

Iqbal, Muhammad. 2019. "Pemasaran Jasa Pendidikan dan Implementasinya sebagai Strategi Pengembangan Pendidikan di SMP Muhammadiyah 1 Depok Sleman Yogyakarta." Manageria: Jurnal Manajemen Pendidikan Islam, 4(1); 127-146.

Kotler, Philip dan Gary Amstrong. 2008. Prinsip-Prinsip Pemasaran. Edisi Kedua Belas Jilid 1. Jakarta: Penerbit Erlangga.

Minarti, Sri. 2011. Manajemen Sekolah (Mengelola Lembaga Pendidikan Secara Mandir). Yogyakarta: Ar-Ruzz Media.

Moeleong. L.J. 2011. Metode Penelitian Kualitatif. Bandung: Remaja Rosdakarya.

Murfi, Ali, Irwan Fathurrochman, Atika, dan Nora Saiva Jannana. 2020. "Kepemimpinan Sekolah dalam Situasi Krisis Covid-19 di Indonesia." Manageria: Jurnal Manajemen Pendidikan Islam, 5(1); 119-136.

Sugiyono, 2019. Metode Penelitian Pendidikan: Pendekatan Kualitatif, Kualitatif dan REG. Bandung: Alfabet.

Wahyudi, Kacung. 2017. "Manajemen Pemasaran Pendidikan." Jurnal Kariman, 05(01);65-82. 